\title{
THE MICE FOCUSING SOLENOIDS AND THEIR COOLING SYSTEM
}

\author{
M. A. Green, G. Barr, W. Lau, R. S. Senanayake, and S. Q. Yang \\ University of Oxford Department of Physics, Oxford OX1 3RH, UK
}

This report describes the focusing solenoid for the proposed Muon Ionization Cooling Experiment (MICE) [1]. The focusing solenoid consists of a pair of superconducting solenoids that are on a common bobbin. The two coils, which have separate leads, may be operated in the same polarity or at opposite polarity. This report discusses the superconducting magnet design and the cryostat design for the MICE focusing module. Also discussed is how this superconducting magnet can be integrated with a pair of small $4.2 \mathrm{~K}$ coolers.

\section{INTRODUCTION}

MICE consists of a muon cooling channel and two detectors [1]. Three types of modules will be used in MICE. These are the focusing and absorber module, the coupling coil and RF module, and the detector module [2]. The focusing module for MICE consists of a pair of superconducting solenoids that are around a liquid hydrogen absorber, which provides ionization cooling for the muons within the cooling channel [3]. The warm bore tube and one of the focusing solenoid cryostat vacuum vessel form the vacuum vessel that this liquid hydrogen absorber.

The nominal design configuration for MICE calls for the focusing solenoids to be operated in the gradient mode, with two coils each carrying 2.01 MA while operating at opposite polarities. When the MICE focus coils are operated in the gradient mode, a large inter-coil force is developed in the direction to push the two coils apart along the magnet axis. This force must be carried by a cold aluminum structure between the two coils. There are configurations of the experiment that call for the two focusing coils to operate at the same polarity. When the magnet operates in the solenoid mode, the inter-coil force pushes the two coils together along the magnet axis. This report presents a number of design parameters for the MICE focusing solenoid system and its cryogenic cooling system.

The high cost of a central refrigeration system suggests that the MICE magnets can economically cooled using small $4.2 \mathrm{~K}$ coolers. As a result, the magnets for MICE have been designed so that they can be cooled using one or more small 4.2 coolers. The attachment of these coolers to the magnet can have a strong negative effect on the magnet temperature at the high field point in the magnet, if this attachment is not done correctly. A section of this report will deal with the attachment of the coolers to the magnet.

\section{DESIGN PARAMETERS FOR THE MICE FOCUSING MAGNETS}

Figure 1 shows a cross-section of the MICE focusing magnet in its warm bore cryostat. The liquid hydrogen absorber fits into the warm bore of the magnet with its liquid hydrogen and liquid cryogen cool down pipes passing around the end of the magnet. The magnet coil and the liquid hydrogen absorber will be cooled with small coolers. Since the cool down time of the system is of importance, the cool down of both the magnet and the hydrogen absorber will be done using liquid nitrogen and liquid helium.

Table 1, presents the basic physical and electrical parameters for the MICE focusing magnet during its normal operating mode (when the muon average momentum $=200 \mathrm{MeV} / \mathrm{c}$ ). When the two coils are powered at opposite polarity, a $2350 \mathrm{kN}$ force that is pushing the coils apart is created in the longitudinal direction [4]. When the coils operate at the same polarity, the force is about $1000 \mathrm{kN}$ pushing the coils together. The cold mass support peak force is about $200 \mathrm{kN}$, for any of the MICE operating modes. 


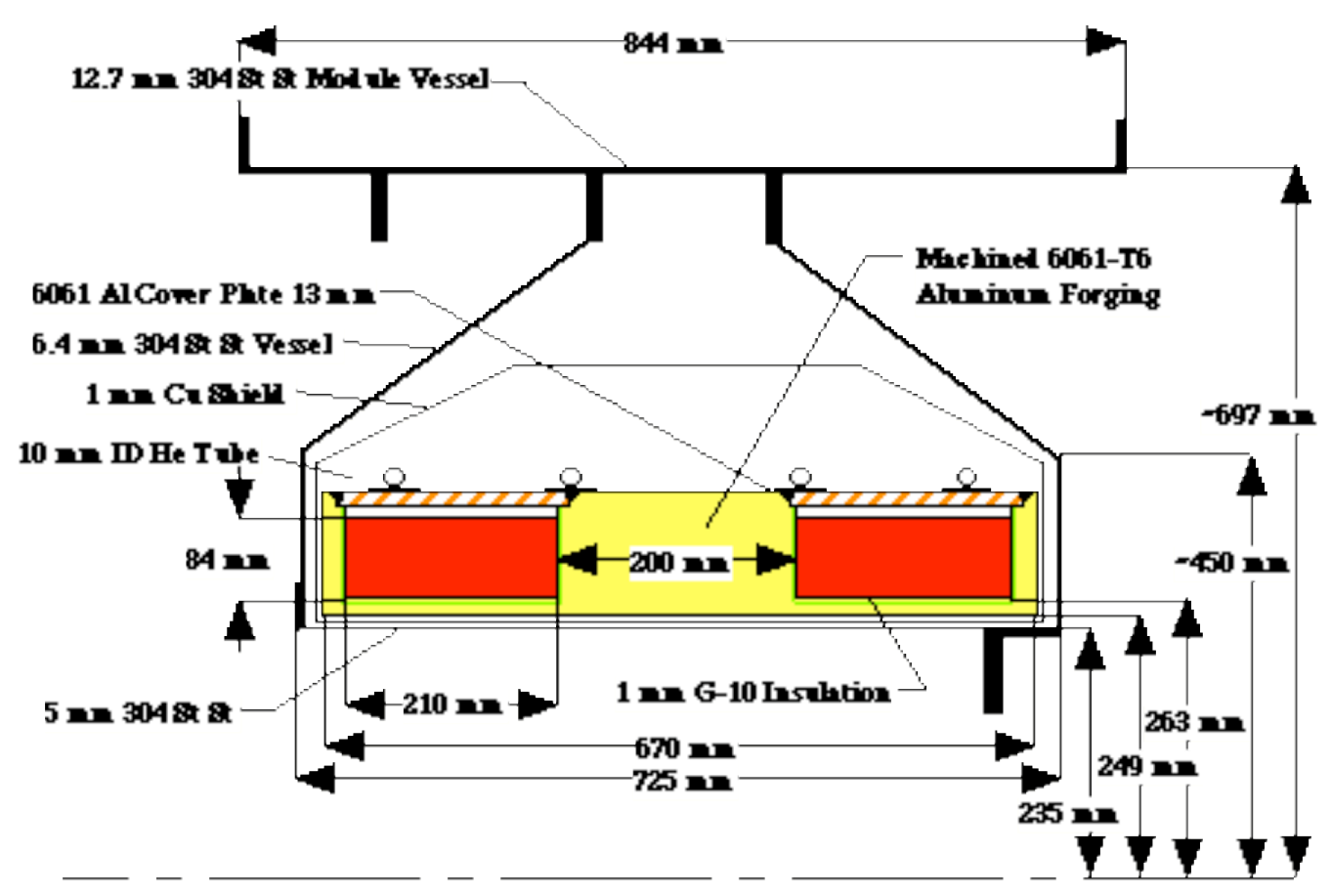

Figure 1. A cross-section of the focusing magnet, showing the key dimension of the coil and cryostat

Table 1. The basic design parameters for the MICE focusing magnet

\begin{tabular}{lclc}
\hline \multicolumn{1}{c}{ Magnet Physical Parameters } & \multicolumn{2}{c}{ Magnet Electrical Parameters } \\
\hline Coil Inner Radius (mm) & 263 & Magnet Self Inductance (H) & $\sim 138$ \\
Coil Length (mm) & 210 & Magnet Design Current* (A) & 208.3 \\
Coil Thickness (mm) & 84 & Matrix Current Density J* $\left(\mathrm{A} \mathrm{m}^{-2}\right)$ & 156.6 \\
Distance between the Coils (mm) & 200 & Magnet Stored Energy* (MJ) & $\sim 3.0$ \\
Number of Layers per Coil & 76 & EJ $^{2}$ Limit for Protection* $\left(\mathrm{J} \mathrm{A}^{2} \mathrm{~m}^{-4}\right)$ & $7.3 \times 10^{22}$ \\
Number of Turns per Coil Layer & 127 & Peak Induction in the Winding* $(\mathrm{T})$ & $\sim 6.39$ \\
\hline * The magnet design current is for the solenoid in the focus mode a $\square=420 \mathrm{~mm}^{22}$ and $\mathrm{p}=200 \mathrm{MeV} / \mathrm{c}$
\end{tabular}

Figure 2 shows the load line and the temperature margin for the superconductor chosen for focus coils. The design points represent the standard operating case and a case the takes the conductor nearly to its critical current. Figure 3 shows the temperature distribution in the magnet when it is cooled by a small cooler at one place on the focus coil package [4]. Large temperature differences can result from this.

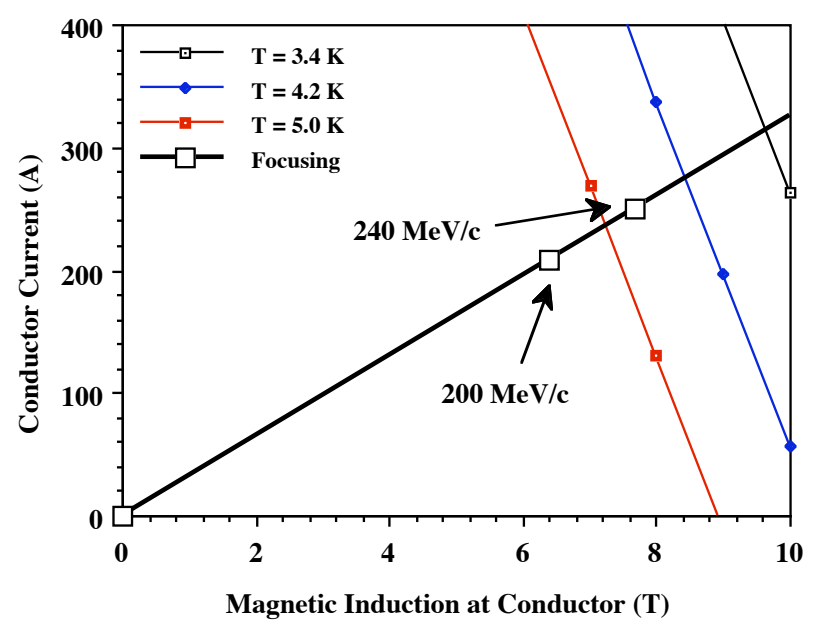

Figure 2. Magnet load line and the Ic of the magnet superconductor (The magnet design points are shown.)

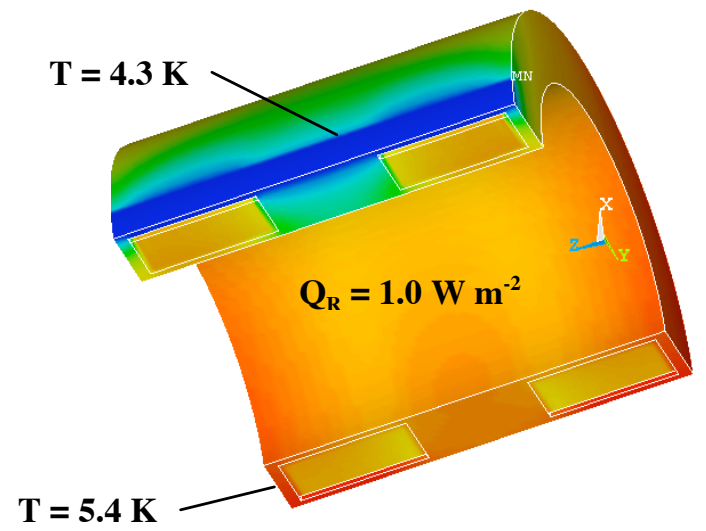

Figure 3. The temperature distribution in the MICE focus coil package when cooled in one place by a cooler 
The focusing solenoid $\mathrm{Nb}-\mathrm{Ti}$ conductor has the following properties; 1) The insulated dimensions are $1.00 \mathrm{~mm}$ by $1.65 \mathrm{~mm}$ with round ends. 2) The copper to superconductor ratio is four. 3) The copper has a minimum RRR $=75$. 4) The twist pitch is $12.7 \mathrm{~mm}$. 4) There are 55 filaments that are $78 \square \mathrm{m}$ in diameter. 6) The conductor critical current is $760 \mathrm{~A}$ at $5.0 \mathrm{~T}$ and $4.2 \mathrm{~K}\left(\mathrm{~J}_{\mathrm{c}}(5.0 \mathrm{~T}, 4.2 \mathrm{~K})=2940 \mathrm{~A} \mathrm{~mm}^{-2}\right)$. The proposed conductor was designed for use in MRI magnets that operate in persistent mode. Since the MICE magnet is a DC magnet with a long charge time AC losses in the conductor are not an issue.

The MICE focusing solenoid has two pairs of 300 A current leads. This allows one to operate the magnet in either the solenoid mode (both coils at the same polarity) or the gradient mode (both coils at opposite polarity). The highest current that the magnet is designed for is about $250 \mathrm{~A}$ when the magnet is pushed for the high momentum cooling tests. There may be other experimental modes that require that both coils be powered separately. As the experiment is better defined, the lead current may be reduced.

\section{COOLING THE FOCUSING MAGNET WITH SMALL COOLERS}

The MICE focusing solenoid is designed to be cooled using two 1.2 to $1.5 \mathrm{~W}$ (at $4.2 \mathrm{~K}$ ) two-stage coolers. The $1^{\text {st }}$ stage of one of these coolers will provide 30 to $40 \mathrm{~W}$ of cooling at $50 \mathrm{~K}$, when the compressor runs on a $50 \mathrm{~Hz}$ motor. The $1^{\text {st }}$ stage cooling goes up 20 to 25 percent when the compressor is run on a $60 \mathrm{~Hz}$ motor. The $1^{\text {st }}$ stage absorbs the heat leak down the cold mass supports [5] and the radiation heat loads to the shield. The largest load on the first stage of the cooler is the heat down the conduction-cooled current leads. The current lead heat load is about $70 \mathrm{~W}$ per kA lead pair at $50 \mathrm{~K}$.

In order to cool the focusing magnet with small coolers, the magnet cryostat must have heat leaks that are less than 1 watt at $4 \mathrm{~K}$. The $2^{\text {nd }}$ stage heat load is primarily from cold mass supports [5], thermal radiation, pipes, and the leads. The current leads between the $50 \mathrm{~K}$ intercept and the $4.2 \mathrm{~K}$ region must be made from HTS material. Even with HTS lead, the lead heat leak into the $4 \mathrm{~K}$ region will be the largest single load at $4 \mathrm{~K}$. The heat loads into the second stage of the cooler are a function of the first stage temperature. If one operates the focusing solenoid on one cooler the first stage temperature would be greater than $60 \mathrm{~K}$ and the second stage temperature will be from 4.6 to $4.8 \mathrm{~K}$. By using two coolers, one can reduce the first stage temperature to $40 \mathrm{~K}$ and reduce the second stage temperature to 3.7 to $3.9 \mathrm{~K}$.

Figure 3 illustrates the effect of heat leaks into the cold mass on the temperature distribution within the magnet [4]. The figure shows that a radiation heat load of $1.0 \mathrm{~W} \mathrm{~m}^{-2}$ will result in a $\square \mathrm{T}$ of $1.1 \mathrm{~K}$ within the magnet. This $\square \mathrm{T}$ is added to any $\square \mathrm{T}$ that occurs between the magnet cold mass and the cooler second stage cold head. For example, if one connects the magnet to the $2^{\text {nd }}$ stage cold head with a copper strap $(\mathrm{RRR}=100)$ and one wants a $\square \mathrm{T}$ of $0.1 \mathrm{~K}$ down the copper strap, a $0.15 \mathrm{~m}$ long strap must have a cross-section area of about $0.0025 \mathrm{~m}^{2}$. The $\square \mathrm{T}$ along strap is proportional to its length and inversely proportional its cross-section area [6]. A magnet can be cooled down through the strap.

It is desirable that the cooling from the second stage cold head be spread around the circumference of the focusing magnet and it is desirable to locate the cooler is a position on the magnet cryostat where cooler maintenance can occur without taking the whole magnet apart. Figure 4 shows a method for distributing the cooling using a thermal siphon heat pipe between the cold head and the load.

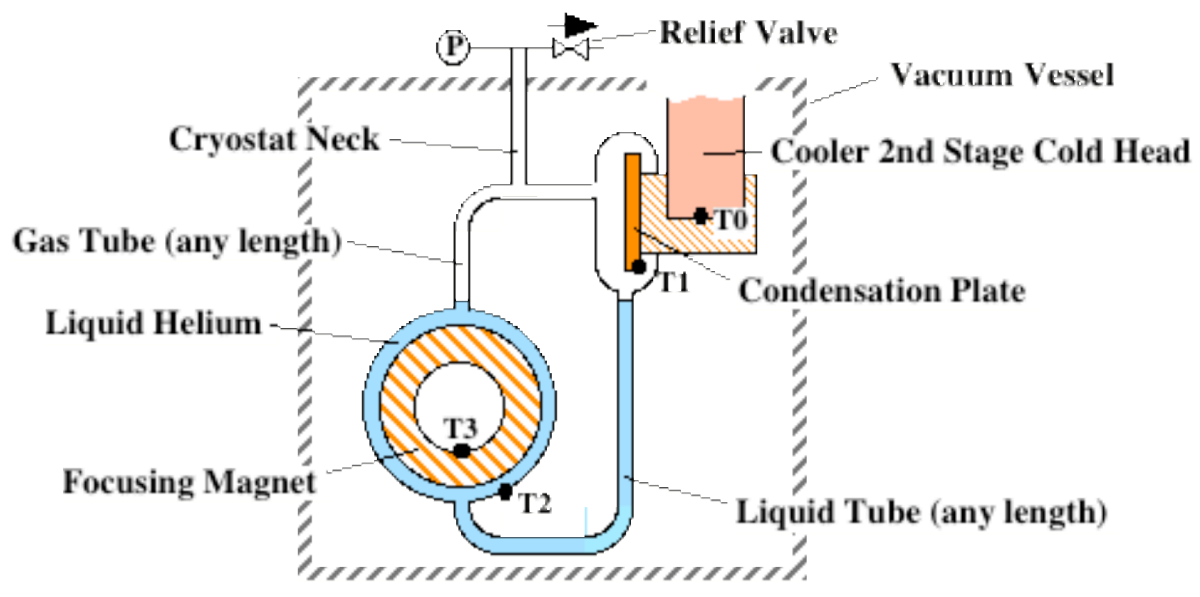

Figure 4. A schematic of a gravity heat pipe for distributing $4 \mathrm{~K}$ cooling from the cooler $2^{\text {nd }}$ stage cold head to the magnet (Note: the liquid helium can be in channels around the cold mass. The channels must be attached to the focus coil spacer.) 
The thermal siphon heat pipe has the following advantages over a copper strap for distributing cold to the focusing magnet coils [7]: 1) Liquid helium can be all around the coil so that the $\square \mathrm{T}$ within the magnet is minimized. 2) If the heat pipe is correctly designed, the $\square \mathrm{T}$ between the $2^{\text {nd }}$ stage cold head and the magnet can be as low as $0.05 \mathrm{~K}$. 3) The heat pipe filters out the $0.25 \mathrm{~K}$ temperature oscillations in the cooler $2^{\text {nd }}$ stage cold head. 4) The coolers can be located some distance from the coil package. As a result the cooler position can be optimized. 5) The space occupied by the helium pipes is small compared to a copper strap with less desirable performance. 6) A heat pipe provides good vibration isolation of the magnet from the cooler cold head. 7) The coolers can be connected separately, each with its own condenser. This permits one to keep the magnet cold (at $5 \mathrm{~K}$ ) on a single cooler while the second cooler is turned off. 8) Liquid helium in the magnet permits the magnet to recover from a short power outage. The disadvantage of using a heat pipe to connect the cooler to the magnet is the magnet must be cooled down to $4 \mathrm{~K}$ using liquid cryogens. Because the focusing magnet cold mass is $650 \mathrm{~kg}$, liquid cryogen cooling will be used to cool the focus coils anyway. The cooler first stage can be used to cool down the $50 \mathrm{~K}$ shields and intercepts.

\section{CONCLUDING COMENTS}

The design of the MICE focusing magnet is well under way. The magnet is designed to withstand the magnetic stress within the coil package. The temperature distribution within the focusing magnet cold mass has been studied. If one cools the spacer between the coils, the $\square \mathrm{T}$ between the cooled point on the spacer and the hot spot on the aluminum support structure will be less than $0.1 \mathrm{~K}$. A magnet cold mass support system that carries $200 \mathrm{kN}$ in the longitudinal direction has been designed so that its heat leak at $4.2 \mathrm{~K}$ is less than $0.1 \mathrm{~W}[5]$.

With proper design and execution of that design, the focusing magnet can be kept cold using a pair of small $4.2 \mathrm{~K}$ coolers (rated at 1.2 to $1.5 \mathrm{~W}$ at $4.2 \mathrm{~K}$ ). The focusing magnet must be cooled down using liquid cryogens. With proper design, the $\square \mathrm{T}$ between the cooler second stage cold head and the hottest point in the magnet can be less than $0.2 \mathrm{~K}$ [7].

\section{ACKNOWLEDGEMENT}

This work was supported by the Oxford University Physics Department and the Particle Physics and Astronomy Research Council of the United Kingdom.

\section{REFERENCES}

1. "A Proposal to the Rutherford Appleton Laboratory, an International Muon Ionization Cooling Experiment (MICE)," proposed by the MICE Collaboration, 15 December 2002

2. Green, M. A. and Rey, J. M., "Superconducting Solenoids for an International Muon Cooling Experiment," IEEE Transactions on Applied Superconductivity 13, No. 2, p 1373, (2003).

3. Green, M. A., Baynham, E., Barr, G., Lau, W., Rochford, J. H., and Yang, S., "Focusing Solenoids for the MICE Cooling Channel," Advances in Cryogenic Engineering 49, AIP Press, New York (2003)

4. Green, M. A. and Yang S. Q. "Heat Transfer into and within the 4.4 K Region and the 40 K Shields of the MICE Focusing and Coupling Magnets" an Oxford University Report for the MICE collaboration (2004)

5. Green, M. A. and Senanayake, R. S., "The Cold Mass Support System for the MICE Focusing and Coupling Magnets," an Oxford University Report for the MICE collaboration (2004)

6. Green, M. A., "The Integration of Liquid Cryogen Cooling and Cryocoolers with Superconducting Electronics Systems," Superconducting Science and Technology, Volume 16, No. 12, p 1349, (Dec. 2003)

7. Green, M. A., Dietderich, D. R., Marks, S., Prestemon, S. O., and Schlueter, R. D., "Design Issues for Cryogenic Cooling of Short Period Superconducting Undulators," Advances in Cryogenic Engineering 49, AIP Press, New York (2003) 